\title{
Papers
}

\section{Evolutionary implications for touchpoint planning as a result of neuroscience: A practical fusion of database marketing and advertising}

Received (in revised form): 11th May, 2007

\section{Angus Jenkinson}

is Professor of Integrated Marketing at the Centre for Integrated Marketing, University of Bedfordshire, and CEO/Founder of Stepping Stones Consultancy Ltd., a research, strategy and planning service firm.

Keywords touchpoints, contact points, CODAR, attitudes, neuroscience, CRM, database marketing, IMC, communication, planning, evaluation, convergence

Abstract This paper reviews the concept of touchpoint planning based on contemporary research into human psychology, attitudes, loyalty and persuasion, and then describes a model and practical tool for putting this learning into practice based on the CODAR system. It draws from research in three areas:

1 human psychology, which is significantly shifting much of the theory about consumer attitudes as developed over the previous 30-40 years;

2 marketing communication, and in particular integrated communication, from the perspective of both planning and evaluation and

3 database/data-driven marketing, taking brief note of recent developments in digital technology.

Angus Jenkinson Centre for Integrated Marketing University of Bedfordshire Business School CEO, Stepping Stones Consultancy Ltd. Grange Farm Barn Upper Dean PE28 OLT, England

Tel: +44 8456588856 ;

e-mail: angus.jenkinson@ stepping-stones.org

The approach is unusual, since it borrows from advertising research to develop best practice in database marketing/customer management, which it is proposed will in turn be useful to conventional advertisers. By focusing on the most difficult and complete area of branded communication, that is, branded personalised communication, such as a customised webpage or interactive television, and applying the standards from across all marketing communication disciplines to develop an integrated model, useful learning is derived for practitioners focused on both personalised communications and mass/segmented depersonalised communication, such as advertising on traditional television channels. Journal of Database Marketing \& Customer Strategy Management (2007) 14, 164-185. doi:10.1057/palgrave.dbm.3250054

\section{INTRODUCTION}

After a brief survey of the concept of touchpoint planning as it has developed over the last two decades, the paper will develop in four sections:

1 Since the paper involves a review of the theories that have dominated 
communication planning for decades, it will be prefaced with a brief review of the nature and role of scientific paradigms, as outlined by Thomas Kuhn. This will conclude with defining the requirements for any comprehensive model of touchpoint planning.

2 A review of established understanding of consumer attitudes and their relationship to behaviour follows, drawing on neuroscientific evidence, suggesting that the dominant theory of the last few decades has been too focused on cognitive processing. A better understanding of the human mind and the process of persuasion, decision-making and loyalty formation provides a more comprehensive, accurate and effective theoretical model for the development of consumer insights, communication planning and evaluation. It also simplifies and clarifies the task, resolving several research difficulties that have existed for decades. It also explains why integration is necessary and why the separate development of the various communication disciplines, such as advertising, sales promotion and direct marketing, has led to distortion of our understanding of the communication task.

3 Thirdly, it will outline a communication planning tool, CODAR, which has been demonstrated to use this theory effectively to enable integrated planning and communication, ensuring that the framework for planning and evaluation is common across every communication event.

4 Finally, the paper will conclude with suggested implications for development.

\section{TOUCHPOINTS AND TOUCHPOINT PLANNING}

There are numerous definitions of 'touchpoint', a construct that arose in the 1980s based on a method developed by Jenkinson $^{1}$ and popularised by OgilvyOne. There is, however, general agreement that it refers to a point or moment of contact/ communication between an organisation or brand and an individual consumer or stakeholder. There are also a number of synonyms or related concepts including 'moments of truth', which refer to critical incidents or more decisive touchpoints, 'media', since anything that conveys a message is a medium, 'service point/service encounter', 'interaction' and 'customer experiences'.

Touchpoint planning is a comprehensive approach to designing, managing, executing and evaluating personalised customer communication and experience.

While the emphasis on integration has increased, to think that marketers have not aimed to integrate communication before is to duck reality. Each generation has a tendency to reinvent old ideas in new words. The crucial differences have been the increasing costs and channel diversity of television, making mass advertising harder, along with the development of the computer, the customer database and the consequent development of database marketing leading to CRM and internet marketing. Database marketers proposed identifying customer touchpoints and then using this to develop a marketing strategy and customer marketing database. For example, Jenkinson ${ }^{2}$ described how marketers could identify the current and required customer experience at each touchpoint (or moment of truth) as well as information...

1 Customers would expect the brand to use to provide the appropriate customer experience, such as the customer's name, product holdings or interests, and past relevant experience;

2 Needed by marketers to increase the relevance of the selling/marketing message, for example, information that improved segmentation and personalisation or that identified what the customer might want to buy;

3 Useful to capture for application at another touchpoint.

In practice, this led to further polarisation between practitioners focused on managing 
contacts with customers that used addressable, 'one-to-one', database-driven communication, as for example in CRM/ customer management, and those who used broadscale, paid-for advertising media. Although touchpoint planning theoretically applies to all consumer contacts, database marketing (and its offspring) led to increased focus on direct, personalised and interactive communication. Thus touchpoint planning in practice applied to personalised, interactive media such as the mail, telephone and web, while media planning referred to advertising's use of 'paid for media', such as television, radio, press and posters. Many organisations developed two or more marketing communication groups, one responsible for CRM and the other for advertising, both aiming to achieve integration. In this structure, sales promotion often had an ambiguous relationship, aligning with advertising when promotions were relatively anonymous and with CRM when they were linked to loyalty schemes. PR, sales and service were also commonly managed by separate management groups with different associated agencies.

There was a corresponding polarisation of knowledge, communication objectives and evaluation metrics, with advertising, for example, measuring ad awareness while direct marketing measured behavioural response. This continues to be perpetuated by professional institutes/councils and media. For example, WARC, the World Advertising Research Council, focuses on issues related to 'advertising' with less attention given to direct communications. A key task of an integrated approach to touchpoint/communication planning is to be able to relate the different communication objectives to each other in order to optimise the experience of consumers and to improve evaluation.

A fully integrated framework of communication planning would allow for integrated planning and evaluation of communication across all touchpoints: paid-for media and directly managed touchpoints, including online, offline and human interfaces with customers. Most senior marketers are now committed to developing such an integrated approach, although they may be cautious or uncertain about how best to do this. In particular, a clear, easy to use model and method that is soundly based in the theory of communications and consumer psychology is required. Most leading media-planning agencies are now developing or seeking to develop tools and competences for planning media across the entire spectrum. An associated task that cannot be ducked by marketers involves an integrated approach to communication content, that is, the creative message. This is the central theme of this paper.

Every communication touchpoint, by whatever medium, channel or method, will be mentally processed by consumers. While each person is different, there is a broadly common psychological structure belonging to all human beings. Communication planning tools should correspond reasonably with how human minds actually work. Furthermore, given that each consumer is an individual with one brain processing all communications, it is reasonable to believe that a single model can be used for all forms of communication planning. While such a method would need to respond to different media characteristics (sitting watching ads before a film in the cinema is different from reading a letter from the bank at work) and the differing communication objectives, these also both manifest as facets of mental experience.

Before describing how this might work. It is useful to review the nature of paradigms, the dominant paradigms of the last few decades and the emerging revolution in contemporary theory.

\section{PARADIGMS AND THE MARKETING PARADIGM}

Thomas $\mathrm{Kuhn}^{3}$, in one of the more influential books of the 20th century, 
defined for the first time the concept of 'paradigm' as it relates to the development of scientific theory. Kuhn described how paradigms provide an agreed framework of understanding for scientists (and this includes marketing theorists and researchers). This framework shapes what is interesting, valid and meaningful in scientific research, posing problems that need answers but also defining the boundary within which those answers are expected. Prior to the establishment of a paradigm there is a crisis period with multiple often conflicting theories that operate in parallel with each theorist commonly required to begin from first principles within their field. The establishment of the paradigm provides order and enables rapid progress since everyone operates within a shared frame of reference (while anyone outside this frame of reference is excluded from being considered as a serious scientist; indeed the application of the term in common use to mean a way of seeing the world that excludes other ways of seeing has its origins here). As a result of the paradigm, it is no longer continuously necessary to return to first principles, but each researcher can build on the edifice of prior knowledge, and this is why within the framework knowledge can advance so quickly.

Kuhn demonstrated how human knowledge progresses by rapid evolution within a paradigm followed by revolution to a new paradigm, with each prior paradigm typically remaining useful at a subsidiary level (as eg Newtonian physics is still the bedrock of most engineering and Euclidean geometry still of considerable use in various mathematical applications) while subsumed in the more comprehensive theory.

The crucial point however is that, during each stage in which a paradigm operates, experts are agreed that it represents the best approximation to the truth (or even the truth) and that all that remains is to resolve a few relatively minor problems to achieve a perfect understanding. Furthermore, they are blinded to alternative ways of interpreting the data. For this reason, Eisner ${ }^{4}$ explains: 'Knowledge is always constructed relative to a framework, to a form of representation, to a cultural code, and to a personal biography'. By contrast, a revolution involves considering, at the least, the same data but arriving at a different interpretation. An equivalent process appears to be taking place in marcoms.

\section{From scientist to man on the Clapham omnibus}

There is clearly a significant gap between the theoretical scientist and the proverbial man (or indeed woman) on the Clapham omnibus. Furthermore, many practitioners consider that they follow pragmatic, practical approaches that have little to do with academic theory. This however ducks the issue of how people decide what is pragmatic and practical. The paradigms of high science, such as Darwinism, trickle through to become dominant ideologies on the high street, influencing business behaviour. Through the agency of teachers at school and university, the influence of consultants and more theoretically inclined practitioners and practitioner literature, many theories are simplified to 'essential elements' and packaged to be more palatable and thus become adopted on a widespread basis. In the process, the originating theory may be formally lost but the underlying principle adopted. The example of the Elaboration Likelihood Model (ELM) will be discussed below.

Furthermore, practitioners live within a society which is broadly shaped by paradigms that influence us, often in surreptitious or unconscious ways, from birth. The psychological theories of behaviourism and cognitive science, both of which will be discussed below, have generated a host of influences on the structure of social organisations, attitudes and human behaviour in ways that the person on the Clapham omnibus, or indeed 
the astute marketing practitioner, may not be aware.

\section{Marketing paradigms}

Applying this understanding to review of marketing since the last world war suggests that paradigms emerged for advertising planning, direct marketing, market research and other disciplines. During the 1990s, a crisis in media and communication planning arising from a mix of factors, particularly the changing economics of the media, as media channels proliferated and television costs inflated, and the goal of integration as a superior planning method, gained force to the point where the goal of integration is widely accepted while the method of achieving it has not yet been agreed. This paper suggests that one of the more important reasons is that limited and fragmented communication theories are a barrier to effective media/touchpoint planning.

Two principal theories have coexisted within and to some extent contested the field of marketing communications during the 20th century, each achieving near paradigmatic status within its own domain. They may be called the behavioural school (not to be confused with the related behaviourist school of psychology) and the attitudinal school of communication planning (concepts related to the ubiquitous terms: below the line and above the line). Amongst practitioners, these are sometimes regarded as complementary methods or marketing domains rather than alternative paradigms. However, the paper suggests that the width of the division arises from an artificial conceptual distinction, and that a 'theory of everything' is therefore possible.

The behavioural school tended to dominate direct marketing in all of its various forms. In this paradigm, marketers focused on pragmatic analytics based on the actual behaviour of consumers. They have, for example, analysed transactions on the basis of recency, frequency and monetary characteristics; they have analysed response rates and created segments based on behaviours. Perhaps the most sophisticated exponent is Amazon, which has developed advanced algorithms generating next-bestactions based on statistical analysis of the consumer's behaviour at the website. It is true that many practitioners and commentators have emphasised the importance of attitudinal effects and the establishment of attitudinal objectives in briefs is not uncommon. But it is also the case that evaluation is dominated and considered to be rightly dominated by behavioural metrics. For example, British Gas advised in 2004 that despite having a larger budget for direct mail than television they used virtually no qualitative research to evaluate attitudinal effects of the mail, because they had never thought of doing so.

Advertising has been dominated by the attitudinal school, aiming to create consumer attitudes that influence buying behaviour and brand equity. Research into brand attitudes then follows as a primary evaluation tool.

While these two paradigmatic groups do not exhaust all marketing communications disciplines, they do provide a reasonable framework within the limited context of this paper for consideration of other disciplines. For example, PR would largely be seen as another route to creating the kinds of effects generated by advertising while sales promotion is generally a behavioural tool.

The first object therefore for any comprehensive touchpoint planning model would be to unite these two schools of thought in a higher order.

While the 'attitude' construct is, however, probably the single most important in the fields of social psychology and advertising, there have been continuous difficulties in proving and measuring the role of attitudes in decision-making and behaviour. Scientific revolutions often take place when new technology changes the data available to 
scientists. Neuroscientific research is revolutionising understanding of attitudes, and interestingly reinforcing theories that are over a century old. The attitude paradigm as it has operated is therefore in crisis. Fortunately, this new perspective leads to a new shared higher order model and consequently enhanced touchpoint planning.

\section{HOW MARKETING COMMUNICATION WORKS}

This section begins with a review of how attitudes have been conceived for at least the last 50 years and will then describe a more effective understanding of attitudes. This will then provide a basis for describing the communication planning tool in the next section. It is intuitively and practically obvious to most marketers that consumer attitudes influence what consumers buy. There is a substantial body of research proving the relationship between attitudes 5 (as generally conceived) and consumer behaviour, ${ }^{6}$ although there is also research claiming no clear relationship or allowing advertising only a weak effect. ${ }^{7}$ Such research was used as evidence by the tobacco lobby to argue for continued advertising rights and more recently a senior member of the marketing industry used the unproven effect as justification for food brands to advertise to children. ${ }^{8}$ Most such issues arise from how the research project has been implemented ${ }^{5}$ or, more importantly, from the operating paradigm: the theoretical principles on which research was based can now be seen as dubious. ${ }^{9}$

\section{What are attitudes understood to be?}

Already, by 1935, Gordon Allport could remark: 'The concept of attitude is probably the most distinctive and indispensable concept in contemporary American social psychology. No other term appears more frequently in experimental and theoretical literature. As may be expected of so abstract and serviceable a term, it has come to signify many things to many writers with the inevitable result that its meaning is somewhat indefinite and its scientific status called into question'. Nevertheless, attitudes have continued to dominate marketing development, particularly in the field of advertising.

Allport provided a classic 1935 definition: 'An attitude is a mental and neural state of readiness, organised to experience, exerting a directive or dynamic influence upon the individual's response to all objects and situations with which it is related'. This was summarised as: 'Attitudes are learned predispositions to respond to an object', ${ }^{10}$ although he noted such 'preparation or readiness for response' may vary from the 'most latent, dormant traces of forgotten habits' to motivating influences that initiate behaviour.

This core concept of attitudes continued. A particular nuance however developed, namely the cognitive learning and evaluation process, to which an opinion is related. Thus for Kotler et al., ${ }^{11}$ an attitude is: A person's consistently favourable or unfavourable evaluations, feelings and tendencies towards an object or idea [my italics]. Solomon et al. ${ }^{12}$ in another leading textbook (remembering that textbooks represent the paradigm) go even further, describing an attitude as: 'A lasting, general evaluation of people (including oneself), objects or issues'.

There is a further persistent strand, relating attitudes to its three components, namely the Cognitive (thinking), Affective (emotional) and Conative (intentional, action) dimensions, typically linked as a sequential process known as a hierarchy of effects, which will be returned to later. For the moment, while attitudes are very commonly related to the cognitive and affective dimensions, and sometimes specifically and exclusively to the affective, the evaluative element tends to push the concept as practised in the direction of the cognitive. While the cognitive element is 
important, this is too strong an emphasis. Furthermore, even theorists and practitioners who promote the affective dimension may phrase attitude statements in cognitive terms ('I feel that church services give me inspiration and help me to live up to my best during the following week ${ }^{13}$ ) or require an evaluative and therefore cognitive response, as for example in several satisfaction and attitude research methods, such as the Semantic Differential Scale.

\section{The cognitive school and its influence on ELM and 'attitudes'}

The Cognitive School of psychology has provided the most significant opposition during the post-war period to the Behaviourists. To behaviourists, attitudes as such are not important; indeed they are not even certain to exist. Behaviourists replaced attitudes with conditioned responses, which of course share the same characteristic of being learned and providing a predisposition to act in a particular way. Cognitive scientists, while frequently acknowledging that conditioning does take place, emphasised the importance of evaluation and conscious learning in shaping attitude and behaviour and this underpins much of the contemporary understanding of attitude. The correspondence with the behavioural and attitudinal schools of communication is clear. Contemporary neuroscience is challenging both psychological theories and leading to a new model for communication planning. ${ }^{14}$

The highly influential ELM is an important example of how the cognitive school influenced the development of advertising and the notion of attitudes. (Even advertisers who have never heard of ELM are likely to be influenced by its precepts, as suggested by the discussion of the man on the Clapham omnibus.) ELM was developed by Petty and Cacioppo ${ }^{5}$ in their landmark 1981 text, which reviewed what they identified as the seven main theoretical strands related to attitudes and persuasion. They then developed a single unifying model, namely the ELM, based on what they identified as the common elements across all evidence-based theories (note that according to the theory of paradigms, only evidence that fits the paradigm will be considered evidence). ELM identifies (pp. 262-268) two basic routes to attitude change: a 'central one' that is taken when persuasion results from thinking about the issue or arguments under consideration [my emphasis] and a 'peripheral one' that results from non-issuerelevant concerns such as impression management motives, the attractiveness of the messages source or one's social role [again my emphasis]. This model then formed the basis of a later detailed exposition in a 1986.

Essentially, this theory provides primacy in the development of persuasion to the cognitive process. There is also a clear relationship between the increasing importance of cognitive evaluation in the concept of attitude and the ELM model. This would mean that in evaluating communication (as a result of touchpoint planning), emphasis would be given to the 'right' opinion or cognitively derived evaluation as the preferred objective.

The multiattribute attitude model is another related influential development in attitude thinking, which also gives primacy to the role of cognition. According to this model, consumers have beliefs about specific brand, service or product attributes and attach different levels of importance to these attributes. Using this approach, an attitude towards a particular brand is based on a series of beliefs about the brand's performance on various attributes and the importance attached to these attributes. Those beliefs that are activated and form the basis of an attitude are referred to as 'salient beliefs' and the responsibility of marketing/marketing communications is therefore to identify and understand the salient beliefs and how they vary according 
to different market segments/communities, over time, across different consumption occasions. The communication strategy involves changing the strength of belief on important attributes, changing the importance or value of an attribute (emphasising strengths of the brand), adding new attributes and changing perceptions of belief ratings on competing brands. The target of communication is therefore beliefs, which are largely conflated with attitude.

The multiattribute model also leads in turn to satisfaction studies rating importance and performance of products, services and touchpoints. While study of satisfaction is important, the essential characteristic is that it asks the consumer to make an evaluation, thus it is not directly exploring the emotional response but rather the cognitive response to the experience.

Giving importance to cognition is natural and not without justification. Cognition plays a somewhat similar role as data to the sun and moving planets in pre-Copernican astronomy. Just as the sun is very obvious, so is thinking. Everyone does it, everyone is aware of doing it, and even the process of deciding how important it is requires its use. By contrast, emotions/feelings and intentions are considerably less clear and obvious. Furthermore, the development of the computer and artificial intelligence has provided an appealing model for how intelligence works.

\section{Thinking, feeling and intentions: The problem}

There have been two principal problems limiting understanding of the three widely agreed components of attitude, namely cognition, affect and conation ('CAC'), or to use their more friendly terms, thinking, feeling and willing (or intentions). The first has already been referred to, and will be returned to, namely the primacy of thinking in mental consciousness. Since this is what everyone, and in particular theorists, is most aware of, it naturally comes to the fore. The second has been the application of CAC to the hierarchy of effects model, which has been extremely influential in advertising for more than a century while being successively dismissed by many researchers as having no sound evidence to support it. Research among UK advertisers and agencies reported in 1991 showed that the most commonly used advertising model was the persuasion hierarchy of effects model. ${ }^{15}$ Well-known versions include DAGMAR and AIDA.

The hierarchy of effects concept is concerned with moving the consumer through successive stages towards purchase and repeat purchase through the act of communication. In the realm of database marketing, there is a related concept of a loyalty ladder. There has been endless research and debate about the sequence of thinkingfeeling-willing that consumers do or should go through for advertising to be most effective. Lavidge and Steiner ${ }^{16}$ were influential in developing a three-phase psychological model, see Figure 1, relating the hierarchy of effects to the three attitude components. This leads to the generalised notion that the consumer response to advertising follows a response path that flows from cognition to affect to behaviour $(\mathrm{C}->\mathrm{A}->\mathrm{B}){ }^{17}$

Vakratsas and Ambler ${ }^{18}$ reviewed more than 250 journal articles and books to

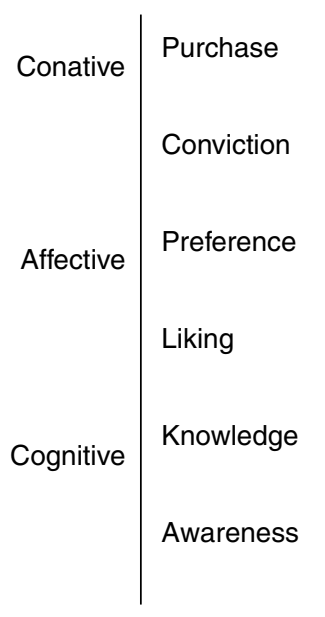

Figure 1: Model of advertising influence developed by Lavidge and Steiner: consumers move from bottom to top 
conclude that although effects hierarchies have been actively employed for nearly 100 years there is little support for the concept of a hierarchy of effects as a temporal sequence. The prevailing paradigm has privileged cognition and focused on a too rigid temporal sequence.

The error is to conflate two completely different consumer characteristics: (1) the attitudinal state the consumer may have, which might be measured or evaluated using something like a loyalty ladder; and (2) the process by which communication experience is internalised. The status of a consumer in relationship to the brand is not the same as the process by which an individual experiences and internalises communication, although they are related.

The loyalty ladder is a valid construct, even if the optimum way of measuring it may be in debate. Indeed, the whole concept of marketing and marketing communications would be rendered invalid if this was not true. WPP in collaboration with their research agency subsidiary, Millward Brown's, have developed the Brandz research tool, which clearly demonstrates a hierarchy of consumer relationships across thousands of brand/ market combinations showing that greater loyalty/commitment generates higher economic worth. Similarly, the commitment or conversion research model developed by Hofmeyr and Rice ${ }^{19}$ has decisively measured in thousands of research studies varying levels of consumer commitment to the brand with corresponding influences on consumer worth and response to advertising and marketing communication.

\section{Excessive focus on emotion}

The complementary problem consists of giving primacy to emotion, which may be emerging as the contemporary preference. For example, $\mathrm{Hall}^{9}$ provides a reverse hierarchical model, affect - behaviourcognition, while Heath et al. ${ }^{20}$ suggest that only emotion is correlated with buying response. To focus exclusively on emotion is again to duck the key issue: emotion is only one element of the mind.

\section{The triune brain and human attitudes}

Using a variety of different research techniques, ${ }^{21}$ neurologists have been reinterpreting the human brain. It is suggested that it has three subsystems, giving rise to the triune brain model described by neurologist Paul MacLean. ${ }^{22}$ Each of the layers or 'brains' or subs-systems (the R-complex, limbic system and neocortex) is understood to have evolved successively. Each is geared toward separate functions of the brain, with its own special intelligence, its own subjectivity, its own sense of time and space and its own memory, but all three layers interact substantially. ${ }^{23}$ Whereas it had previously been assumed that the highest level of the brain, the neocortex, dominates the other, lower levels, MacLean has shown that this is not the case, and that the limbic system, which rules emotions, can dominate higher mental functions when required.

Although MacLean emphasises their independence, it is generally understood to be more accurate to say that they interact. Each more recent layer also augments the capacity of the layer below it while having some ability to override it. Thus, the existence of cognitive, affective and conative dimensions is supported by underlying neural structures, but the hegemony of the cognitive needs to be tempered.

Numerous other scientists have also been researching the brain and mental processes with further surprising findings, notably the work of Antonio Damasio ${ }^{24}$ and colleagues. In his landmark 1994 book, Descartes' Error he described how research has demonstrated the central role of emotion in decisionmaking. More recently, a major US study confirms that emotion plays an integral part in the decision-making process and that emotions even play a role in moral judgments. ${ }^{25}$ 
Daniel Goleman ${ }^{26}$ has popularised the concept of emotional intelligence, demonstrating its role in decision-making and human performance. Goleman ${ }^{26}$ also indicates that emotional intelligence requires an interaction between thinking, feelings and intentions, involving self-aware, knowing employment of the emotional realm.

This does not deny a role for cognition in decision-making; rather it changes the nature of that role. Intellectual and logical analysis, the rational approach, has the effect of setting up the scales for judgment. In the case of decisions genuinely requiring higher levels of rational input, the quality of input, for example, clarity, evidence, logic and reasonableness, will affect the level of emotional comfort with and trust in the proposed plan. In the case of an evaluation of two mortgage products, financial and other analysis by the consumer will lead to an assessment of their functional characteristics, technical risks and pricing; if analysis shows that they are functionally equal but one is cheaper, this will feel like a happier choice. If the products are, however, supplied by two different brands and the consumer has a different history with them, for example, having had positive experiences of the more expensive brand and negative experiences of the cheaper brand, these emotions will also evoke new thoughts about the two brands for the intellect to grapple with as well as predisposing the consumer to the brand with happier memories. This will therefore be a more complex choice.

While emotion is important, so too is intention, desire and determination. While human beings do not always do what they decide or intend to do, this does obviously influence behaviour. Intention does not operate in isolation; ideas and emotions routinely influence what we intend to do. Nevertheless, it is impossible to duck the role of intention as a factor separate from cognition and affect.

One pedagogical movement, the Steiner or Waldorf schools association, the largest single independent schools movement in the world, has been applying since 1919 a philosophy decades ahead of its time that aims to balance the development of cognitive, affective and conative faculties. ${ }^{27}$ According to their successful methods, children reprise the evolutionary development of the human being during their early years, so that during the first seven years (until the change of teeth) education emphasises the development of the conative dimension, from here until puberty they focus on the development of the emotional intelligence of the child and only after puberty does cognition, and therefore intellectual development, take the most prominent role. During each later stage teachers continue to work in a variety of deliberate ways with previous developmental phases. Research has shown that this leads to well-balanced, confident and competent, autonomous adults.

\section{Thinking, feeling and willing: An experiment}

Neuroscience and pedagogy have therefore confirmed an important strand of psychological theory for a century: the three elements of mind, knowledge/ cognitive, affective/emotional and conative/ action interact, and will to some extent be collectively engaged in decisions that lead to behaviour.

A little experiment addressed directly to you the reader demonstrates their working. Figure 2 shows a simple illustration of an animal.

The reader who looks is likely to recognise the animal from its form immediately. This capacity gave rise to the psychological theory of Gestalt (which means form) and is a primary role of cognition. This demonstrates a typical initial role for cognition, through the agency of the brain (particularly the pre-frontal cortex) and nervous system; hence, advertisers seek to gain notice, awareness and recognition. 
Not all readers however will have looked at the illustration. To do so required some motivation, a word deriving from a Greek word meaning movement, motion (there is an Athenian bus service of this name). Of course, the emotion might be complex: you might feel manipulated, for example. In this case, before even looking at the image an interaction will have taken place between a thought (I am being manipulated) and a feeling (dislike), which would undoubtedly influence the experience of observing the illustration. Alternatively, it might be pleasant to find a refreshingly different kind of content, leading to a very different attitude. Of course, in practice, most mental processes take place extremely quickly, often measured in hundreds of milliseconds and scarcely come to consciousness, except perhaps as results. So, before even seeing the illustration and recognising it, several attitudinal processes will probably have taken place.

Needs, which arise especially from the interaction of affect and conation, or desire, will also be significant. Depending on whether needs are satisfied, whether simple needs like clarity or higher needs like selfactualisation, very different thoughts, feelings and intentions arise.

The experiment is therefore analogous to the effect of advertising, at least during a brand launch: before consumers experience the product itself their attitude is shaped by the advertisement. An initial suggestion/ advertisement to attend to the illustration is needed. ('A little experiment addressed directly to you the reader demonstrates their working. Figure 2 on page $\mathrm{xx}$ shows a simple illustration of an animal'). This may generate a variety of extremely rapid mental effects. During this process a kind of dance or dialogue takes place between thinking, feeling and willing. It might appear that cognition has primacy, as it might in some cases, but this is also highly influenced by the more prominent awareness of thought in consciousness. Awareness is not the same as influence. Readers may have been either bored or interested when the illustration was introduced, thus 'affecting' subsequent thoughts, feelings and intentions.

Alternatively, readers may have been determined to study thoroughly, bringing strong intention to initial contact.

The experiment goes further. What animal did you see? This is an ambiguous image and can appear as two different animals, see footnote. ${ }^{28}$

Whether readers review the illustration before checking the footnote might depend on whether they had already noticed the ambiguity (through familiarity or exceptional ability), or were motivated to do so. Motivation might be influenced by an emotional reaction, such as frustration, interest or intrigue as well as needs, such as self-esteem. These in turn could be influenced by memory, values and personality (self-esteem, relevance of the subject and prior history).

Those familiar with its ambiguity are in a situation analogous to the consumer familiar with the brand. In this case, their engagement will also have been influenced by past emotional connections with the image, or others like it, for example, those who saw it in a positive situation are likely to bring a positive emotional memory. The emotions connected with memories, or emotional memory, acts as a filter on present experience just as present emotion acts as a filter on memories. Thus, a bad experience like an accident can influence all subsequent attitudes to driving, while feelings of, say, anger with a person will tend to cue memories of everything that he or she has been thought to have done in the past that were not liked. Memories are therefore not like photographs or objects that can just be taken out of a drawer. They involve an act of re-creation, and therefore involve some level of intention or will (at times we can notice the effort of remembering), as well as being mediated by emotion. 


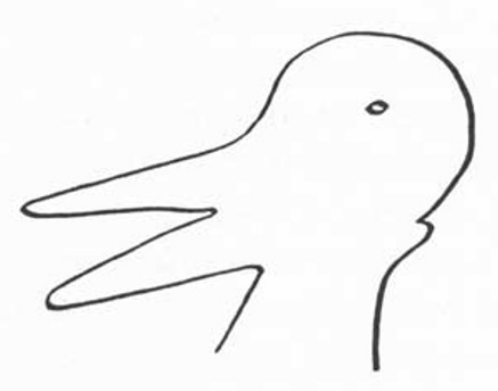

Figure 2: Illustration of an animal

An important characteristic of ambiguous images is that they require an intentional act to shift between modes of seeing. Each requires an act of cognition, and is likely to create an emotional response, such as excitement. This exercise is also a good way to experience intention or determination, requiring as it does a deliberate act. Intention is notoriously difficult to pin down. For example, thinking about moving your arm to turn the page to see the illustration, which it is easy to do and easy to be aware of, does not by itself lead to any action. Something extra — will, which cannot normally be brought to full consciousness - is required to make your arm actually move.

Increasing familiarity with switching between duck and rabbit makes the operation easier, just as less attention/ intention is required for someone familiar with the brand to purchase it again. Eventually, it can in fact become habitual, at which point it resembles an heuristic.

A further aspect of the analogy between advertising and this experiment is the way that the given description pre-and postexperience changes the actual experience of the reader. To have described the illustration immediately as an ambiguous image of a duck and a rabbit would have changed initial experience. Similarly, the postexperience advertisement ('The experiment goes further. What animal have you seen? You might have noticed that this is an ambiguous image and with no change whatsoever other than in how you look it can become two different animals') typically changes initial experience.

Thus advertising both before and after the event alters perceived experience. For example, consumers have been persuaded that bad tasting orange is actually a more flavourful tasting orange, ${ }^{29}$ changing their memories, and their experience. Very few people like beer, cigarettes or coffee on first consumption, but are persuaded (or persuade themselves) by a combination of advertising and social influence ('word-of-mouth'). The greater the strength of positive expectation, the more emotionally affecting will be any perceived dissonance in the experience itself. Interestingly, the more conscious the consumer is of what they expect to find, the greater the likely effect of dissonance, one reason why advertising will thankfully never replace good products and services.

Research in brain/consciousness science has also provided some surprising evidence about the nature of experience. For example, the same sections of the brain are activated in both observers of dancers and the dancers themselves. There appears to be a reflexive activity that enacts what is being observed. That is why an important part of communication is to bring alive the brand, product and/or service, whether visually, verbally or physically, as for example in online travel ads with pictures of beaches or charity mail packs featuring suffering children. Marketing communications are not just about the brand experience, they are part of the brand experience.

A further demonstration of how experience can be influenced is that it is likely that at least a small majority of readers will first notice a duck rather than a rabbit. This is because the word 'duck' or a version of it ('ducked') was used four times earlier in the text, mimicking the techniques of magicians and thus subconsciously cueing or nudging this expectation. There is considerable evidence that 'low attention processing' of advertising 
can have a powerful effect on subsequent decisions and behaviours. ${ }^{30}$ This is often attributed to emotion, but as this example shows, magicians also shift cognitive perception. Derren Brown succeeded in cueing a leading creative team (director and copywriter) to produce a campaign that he had already previously created through a series of low attention stimuli.

During this experiment, readers will have had a variety of thoughts, feelings/emotions and intentions arising from the experience. The nature of the experience and of the thoughts, feelings and intentions are mutually related. For example, the context of the experiment (in a serious research paper) is different from say interacting in a workshop or chatting with friends in the pub, one of whom pulls out the picture. Consequently, it is likely that in each of these occasions or situations there would be some modification of the experience as well as of the thoughts, feelings and intentions, with consequences for touchpoint planning.

Briefly, the nature of value is also clarified by this. Value arises from the satisfaction of need, which is in turn related to affect and desire (conation). An experience is however described intellectually, its importance for the individual lies in its value.

The final important aspect of this interactive process is the way it engages all three elements of the brain in search of confirmation and/or clarification in order to reach an attitudinal conclusion. People personalise their experience, thoughts, feelings and intentions, and also their doubts, concerns and uncertainty, in search for help in resolving them. Barriers have to be overcome before a state of physical and/or psychological intimacy and trust is achieved. Specifically, there is a challenge of credibility and emotional trust in all human relationships. It is for this reason that salespeople are trained in objection handling, while both sales and service people are trained in customer care.
Consumers ask themselves if they understand and if they believe the promise; if their needs are being cared for and if they can trust; if they know, or can visualise what to do next and what will then happen; if it feels good. Unresolved need for help, care and answers will change experience, ideas, feelings and intentions. ${ }^{18}$ Reading a paper such as this, or participating in such an experiment, involves just such questions and evaluation; this demands more intellectual effort than deciding whether a restaurant is the right place to eat tonight, but both involve a consumer's need for help and the care of the writer/service company for the audience.

Marketers therefore need to ask, 'How can I help the person I'm communicating with to get what I want to communicate?' this requires researching what help they might want. The outside of the restaurant needs to be designed in order to help the potential consumer to know what the inside experience will be like and whether they will enjoy it. Thus the exterior appearance of a restaurant should echo and evoke the experience that will be had inside, including such practical issues as the type of food and menu, as well as softer issues such as the personality and quality of the service. On entering the restaurant, new customers seek immediate confirmation that they have made a good choice; hence the critical importance of the first few moments of interaction for customer care.

\section{A summary: The nature of cognition, affect and conation, memory and therefore attitudes}

\section{Thinking}

Through thinking and ideas human beings lay hold of and make sense of the world. Individuals recognise the world around them through concepts and beliefs. Thoughts, ideas, beliefs, concepts and memory pictures are all the result of thinking, in relationship with sense-based 
perception, and represent a finished state: '[it is a] beech tree', [it is an] iPod. There are countless ideas, beliefs and concepts available.

Through the intellectual process individuals are able to discriminate and conclude: this is larger than that; two plus two equals four. Through interaction with memory we can compare a past memory with a present perception ('it was sweeter yesterday'). Through ideas we can see the world differently. Through analysis we can divide objects into categories, recognising the difference between them, and through synthesis bring them together by recognising their commonality. Perceiving that McDonald's and Burger King both supply hamburgers or that the Tesco store has a wider range than Waitrose does not $b y$ itself establish relationship, only knowledge. Intellectual thinking not only does not create relationship it has a tendency to actively distance individual from object in 'cool, objective' contemplation or analysis. (Intellectual processes, thoughts and ideas can be exciting and emotional, just as Einstein evaluated the quality of the theory by its beauty. But this is emotion reacting to the quality or novelty of the ideas, through, for example, satisfaction of needs.)

Ideas and thoughts, once held to be true, become beliefs, but to understand how this happens requires consideration of emotion. Once beliefs are held, however, they influence experience, as was noted in discussing paradigms. For example, ideas about women, children and other groups change how they are seen and consequently emotions and intentions. Once it is 'known' that something is a duck it is initially harder to see it as a rabbit. People who prefer a competitive brand during blind tasting genuinely know that they prefer their favourite brand when drinking it. People who believe that a product will be thought uncool see fault in it. Beliefs are therefore typically a package of emotion and cognition.
Through thinking individuals can also picture the future, such as what it would be like to own a product, or recreate memory pictures, such as remembering what it was like to eat at a restaurant. Both future thinking, or imagination, and 're-membering' require some active intention or will and will be influenced by emotion. It requires very little effort to recognise that it is a table in front of you, a little more to remember what yesterday's table looked like and typically even more effort and desire to imagine a new table.

Every experience is to some extent evaluated by an amalgam of both thinking and emotion, and even intention. Typically, cognition represents to consciousness what has been experienced, and emotions how the individual feels about the experience, although these two interact. Thus all opinions expressing a preference inevitably involve emotional evaluation.

Marketers therefore need to stimulate customers to recognise and have differentiating ideas about their products, services and brand.

\section{Emotion}

Emotions are more active and involving than thoughts. Indeed, if anyone feels involved, excited or disgusted by an idea it is because emotions are involved. Emotion is always in the present tense: the individual feels what they feel right now. A future state can, however, be imagined (through thinking) and emotional response elicited.

Emotions influence memory: emotions evoke memories of times when similar emotions were felt, thus affecting ideas. Research shows that most people prefer the kind of music that they were listening to when they first had sex. Emotions also change thoughts. When individuals feel angry or happy they think differently.

Thoughts, however, also routinely influence emotions: self-beliefs, expectations, representation/interpretation and ideas all generate emotion. Conflicts frequently 
occur because of different interpretations between two parties. ${ }^{31}$

Although emotions can be finely graded, there are only a limited number of core emotions (anger, sadness, fear, enjoyment, love, surprise, disgust, shame and their variations), so that several taxonomies have been created. Although the experience of emotion is entirely personal, billions of people go through the 'same emotions', one reason why it is so universal. Emotions can be stronger or weaker, more or less enduring, hence 'emotions', a softer variant called 'feelings, and 'moods', which are yet more delicate and enduring; but each is composed of the same core set (eg enraptured with love, feeling loving, having a kindly loving mood).

All emotions divide into a broad continuum of liking and disliking: sympathy and antipathy. Through this we are disposed towards moving towards or away from an idea, object or person. Emotion therefore establishes relationship, indeed they are the relationship.

Emotions interact with thinking most importantly in decision-making. It is through the feeling of comfort, trust, happiness with a thought that we decide is true. In the image of Justice with the scales, it is emotion that weighs the scales, weighing whether to move closer or away from the posited decision.

Emotion therefore mediates between an idea and the intention to act on it: does this feel like a good thing to do? Problems with ideas or plans, such as not understanding, not knowing the outcome, finding a dissonance between two perceptions, all lead to emotions, such as anxiety, which block agreement (relationship) and probably action.

Marketers therefore need to build develop strong emotional relationships through positive experiences with their customers.

\section{Intention}

Intention orients to the future: an intention aims to bring about a future state through action, sometimes as a result of years of determined effort and sometimes in the impulse of the moment. Commonly, this will come about through a motivated determination to bring about an idea that has been imagined by thinking, even if this imagination is very fleeting and the motivation very slight. To make a cup of tea normally requires the idea of a cup of tea and some intention, but to decide which kind of tea to make requires weighing up (emotion) different pictures of the future state.

Human beings, however, do acquire habits, so that by repeated actions very little conscious effort is required to do something again. In fact an important aspect of learning is to learn how to do something unconsciously, as for example walking, reading, doing maths or driving.

Individuals are unconsciously active in many bodily processes, for example, remembering to breathe or digest without attention; attending to such processes implies either that something is wrong or signals a deliberate intention to change state (as eg in meditation or diet). Through heuristics we come close to this level of unconscious behaviour, for example, following patterns of behaviour, including purchasing and brand decisions. Such patterns, however, come about only through familiarity, which is an amalgam of recognition (cognition) and emotional comfort/happiness and trust, which is why these are core emotions in consumer relationships.

Marketers therefore need to stimulate initial desire to act and progressively build a more habit-based relationship.

\section{PRINCIPLES FOR TOUCHPOINT PLANNING}

Following this review, five communication elements emerge as critical for touchpoint planning. Applying them represents a truly customer-centric approach. Consumers will inevitably involve at all touchpoint experiences all three aspects of the brain, 
although the importance of each will vary. In addition, establishment of what the experience is and what is thought, felt and intended as a result further involves a cycle that seeks cognitional, emotional and conative confirmation. It therefore makes sense to design communication objectives for all touchpoints based on a varying mix of these five interacting elements which are also applied in the customer-centric CODAR system described below:

1 create experiences that evoke a specific experience of the brand and its value proposition, recreating its personality, idea and feeling; this includes but goes beyond 'tone of voice' to create an experience of value;

2 influence and confirm ideas and beliefs: each touchpoint should be designed to influence customer thinking by stimulating belief in a strong idea related to the brand and/or its core value proposition;

3 stimulate or reawaken positive emotions that establish a specific positive relationship between the consumer and the brand or firm;

4 provide help and confirmation, caring for the likely needs, problems and questions of the individual consumer or segment;

5 stimulate specific desired actions: create a positive action request that does not appear manipulative but arises naturally out of confirmed idea, feeling and experience.

Several further principles emerge for effective Touchpoint planning.

1 The same communication parameters should be applied in all communication planning, whatever the touchpoint, channel or discipline. This provides a consistent, universal approach to planning and evaluation overcoming many of the problems that have previously been noted.

2 Communication briefs that define objectives only in terms of responses fails to define the means of achieving those responses. The most effective communication and greatest learning will take place through a process of evolved understanding of the right communication objectives for each touchpoint and type of customer, through a mix of research and database analysis. For example, qualitative research is required to understand the mind of consumers while database research identifies their behaviour. This means that touchpoint planners must learn to use more effective research.

3 Each brand needs to stand for and evoke a unique value relationship: therefore, these five constituents should collectively create a unique communication experience and value outcome. It is a task of research in conjunction with the brand/product manager and any agencies to define these.

4 The experiences that the consumer has from one touchpoint to the next need to be complementary and consistent. They do not have to be identical, but they should be mutually reinforcing, possibly as part of a touchpoint journey.

5 The relative priority of each of the five communication dimensions will vary from one touchpoint to another and potentially from one customer to another. Therefore, determining the right mix of priorities is a critical element of research and communication planning. Is the most important reason why consumers with relevant needs and resources do not buy a because: they are not effectively triggered to purchase; or have unresolved difficulties about what is on offer; or lack a clear idea of the brand value proposition; or do not have a strong, warm emotional relationship; or are just unable to bring the experience to imaginative life?

6 While mass communication aims to create communications work for everyone, in touchpoint planning the mix of objectives should be varied by community/segment and/or individual.

7 With knowledge comes responsibility: enhanced understanding of consumer attitudes and the processes of persuasion 
lead to enhanced responsibility for marketers. Propaganda and manipulation have rightly been condemned during the 20th century. As marketers come to understand the processes that influence the mind it is ethically and practically important that these are applied in a restrained and responsible way. Failure to do so would in due course inevitably lead to legislation preventing good practice in marketing indications. The lessons of the food and tobacco industries should be learned. Furthermore, history shows that while you can trick most people some of the time you cannot trick them all of the time. In an age of declining loyalties, the effect of bad emotional memories demonstrates the danger of destroying trust and goodwill.

\section{THE CODAR PLANNING TOOL}

Theory is difficult to implement in practice without a system or tool to apply it. Senior marketers will want to provide an easy to use, versatile and flexible, systematic and consistent method to all executives responsible for communication, thus improving overall efficiency and effectiveness and enabling shared learning.

The CODAR system is a proven method of achieving this endorsed by the Media Neutral Planning Best Practice Group. It deploys the five dynamic and inter-dependent planning dimensions outlined above for all touchpoints and all levels of touchpoint planning. Reflecting the above insights, CODAR's five dimensions are organised in a circle demonstrating their dynamic interdependence and enabling the use of a radar chart for planning and reporting purposes. The five dimensions are:

1 Product, service or environment experience: The objective is to give the recipient an experience, whether actual, such as in a product trial, or imaginal, such as through a virtual, visual or verbal representation of the subject or product that stimulates a rich imaginative experience and creates value.

2 Idea forming: influencing ideas, associations and beliefs, for example, about the brand, company or product. This dimension also relates to positioning and proposition in communication planning. In research, it asks how the consumer/customer considers the brand and competitive brands (or other relevant offerings) and what beliefs are necessary to achieve the desired level of change.

3 Building relationship feeling: creating emotional connection: The objective is a feeling of being practically connected with the brand (or business proposal). Examples might be feeling affinity with the values of the brand or culture, feelings of trust and appreciation, feeling valued through being personally recognised and appreciated, knowing representatives of the brand and valuing relationships with them, belonging to some privileged or special group, and involving the brand and its products more in everyday life.

4 Help: The objective is to provide required and perceived help, service or support, for example in the form of information about a product or policy, or help in a process. Here the aim is to reduce anxiety and generate a sense of being cared for, being at ease, trusting, which is a driver of relationship and loyalty.

5 Activation:The objective is to get an intentional or behavioural change, for example, sales activation, sales enquiry or a commitment to behaviour change.

Research shows that CODAR ${ }^{\circledR}$ can be used to plan, brief and evaluate all touchpoints and all levels of touchpoint planning, with significant benefits for 


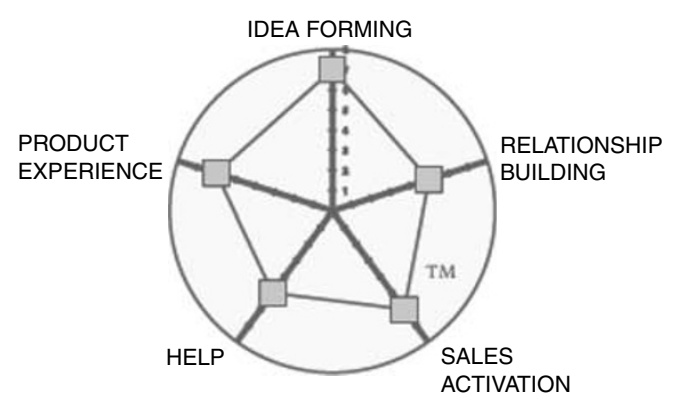

Figure 3: CODAR planning dimensions

efficiency and effectiveness. ${ }^{32-35}$ CODAR is applied in seven steps (Figure 3):

1 An overall business-related goal, such as market share, brand or customer equity.

2 Communication objectives to achieve this goal are defined in a hierarchical and fractal structure from master plan to the lowest level touchpoint, for example, from global brand positioning to community/ segment to channel to channel element, for example, a banner ad, using the same CODAR dimensions.

3 Cascading inter-related CODAR objectives and priorities are specified at each level and for each touchpoint:

(a) Knowledge and insights about consumers and are transformed into specific objectives for each of the five dimensions. For example, a 2002-2003 AA re-branding programme (from 'the 4th emergency service' to 'Just AAsk ${ }^{32}$ ) had an idea forming priority of 6 with the specific objective that motorists believe that 'the AA has a wide variety of relevant products besides roadside coverage'. More than one objective is permitted although users are encouraged to be focused and parsimonious. Where more than one objective is identified, the relative importance is indicated using percentages.

(b) Priorities, that is, the relative importance of each dimension for this level or touchpoint, are expressed numerically (typically on a scale of $1-7)$, which can be shown visually on a radar chart. The relative priorities represent the signature for each touchpoint. For example, the AA could trade on its long experience and emotional relationship with members (and therefore of lower priority, simply needing reinforcement) to focus on getting them to know about the range of its products, which would be the highest priority. Priorities may change over time: for example, during the relaunch of World Rally Championships initial priority was to establish awareness, knowledge and experiential relationship with the brand; subsequently engagement and activation increased in priority. ${ }^{36}$ The CODAR system normally imposes restrictions on the total number of priority points that can be allocated across the five dimensions to force prioritisation. Practically attainable numeric metrics for each planning dimension are used to define 100 per cent success and score achievement on each dimension. Plan versus actual can be reported with two lines on a radar chart and also reported as indexed scores. More than one metric is possible, each being weighted. For example, the AA could have aimed for a 35 per cent increase in the number of AA products known to motorists ('general awareness') and a 22 per cent increase in number of products considered relevant to motorists ('salience'), with the second element contributing 75 per cent of the total. This means that it is possible and practical to have communication-specific methods of evaluation that translate into universal communication objectives. A database holds this information including the translator unit to facilitate econometric analysis. 
4 The CODAR system enables a relationship between lower- and higherlevel communication activities to be defined, so that the contribution of each communication activity to the overall plan is clear and can subsequently be automatically calculated. For example, a multistage touchpoint journey might be defined as a programme with its overall CODAR objectives. Within the programme there might be some direct advertising with a drive to web and follow-up e-mail or sales call. Each of these would have a different priority mix and could have a different significance for the overall success of the programme. Over and underperformance are meaningful and contribution can be normalised against budget.

5 Objectives for communication activities may be held in a database and updated by actual performance (whether derived from research, estimates or CRM/POS systems) triggering performance scores as indicated above. Thus the database can be used for econometric analysis and benchmarking, enabling comparison of different methods, markets, groups, products, media etc. Whereas econometric analysis normally simply relates the amount of spend in a particular channel to the business result, use of CODAR enables functional analysis of the attitudinal drivers of business performance, enhancing skill. In this way, although CODAR assumes the neutrality of all media/touchpoints and disciplines as a starting point, it is possible to identify the performance profile of each touchpoint as well as brand/category profiles and trends, and the performance of different business units, for example, international benchmarking. Inevitably, this requires the collection of a body of data. Used either in conjunction with hard data or by input from a knowledge panel, this can facilitate touchpoint optimisation. If the database is held internationally, then comparison can be international. Comparison can also be made across clients by an agency or consultancy and used for benchmarking or category analysis.

If all communication projects/briefs/cases are CODAR coded, then they can also form the basis of a knowledge management system and the CODAR signature becomes a useful access method for research by employees ("what work has been done in cosmetics that involved the CODAR signature 5-3-3-5-4?'). CODAR can also be applied retrospectively to existing cases to get a fast start and this can also serve as a useful training tool.

The CODAR tool therefore demonstrates a practical way of converting current theory into systematic practice. Users report that it increases the quality of planning and enhances the evaluation capability across mixed media/touchpoints. ${ }^{34}$

\section{CONCLUSION AND IMPLICATIONS}

Database marketing and its related method, CRM/customer management, has developed over the last 20 years into a substantial industry and a major influence on marketing methods. Its success has been based on the accumulation and analysis of customer information, specifically sales and other behavioural transactions, the ability to use this information to deliver more personalised communication, and then the ability to analyse return on investment from marketing activities. It has developed in parallel with and complementing the evolution of advertising and other disciplines that focused on consumer attitudes and mass communication.

Touchpoint planning is a feature of database marketing/CRM that has applied database marketing principles by focusing on mapping customer touchpoints, identifying desirable customer experiences and the information required to achieve these. The techniques developed over 20 
years remain useful but need to be evolved to take account of new findings about the way the mind works.

The increased focus in recent years on mapping customer contact points to enhance customer experience provides a useful bridge. Razeghi and Calder ${ }^{37}$ describe how Disney and Florida Hospital used interaction maps to sketch out customer contact points from end to end of the customer journey, using it as a tool for innovative thinking in how to develop the customer experience. Fortini Campbell ${ }^{38}$ also shows how the analysis of customer contact points can combine traditional skills of database marketing with the precepts of service marketing and the attitudinal insights of brand advertising. Following principles close to those of Jenkinson, ${ }^{39}$ she describes a Brand Contact Inventory tool based on listening to customer stories, listing contact points, evaluating the importance of these contact points and assessing the impressions that customers have of them. It is important to realise that this can be applied as much to a direct mail pack offering a credit card balance transfer as to check in at a hospital.

This suggests that database analysis, research and planning needs to be enhanced compared with common standards. The planning process might include the elements outlined in checklist 1.

\section{Checklist 1: Planning process elements}

1 What general ideas/beliefs, emotional relationships, experiences, help and activation, and their relative strengths, does the target customer community have with the brand?

2 And what are the equivalent for its leading competitors?

3 What insights there are about what would be needed to create a significant increase in customer loyalty/retention and share of category spend?
4 What contact points do customers have with the brand, and are they brand or customer initiated?

5 How is this different from other brands of the category?

6 Which are the most important contact points? Why?

7 What ideas/beliefs, emotional relationships/feelings, experiences, help and activation does the target customer community have at each of these contact points?

8 How does this compare with their experience with leading competitors?

9 What insights are there about the ideas/ beliefs, emotional feeling, experiences and help, and their relative priority, which consumers in the target customer community need to achieve the activation required?

Undoubtedly, database marketers with a history of behaviourist and responseoriented marketing practice will need to upgrade their skills to take advantage of the new learning. At the same time, as digital marketing techniques develop a larger share of customer interactions more personalised advertising communications will follow that benefit from the skills of database marketing. This will progressively be applied to iTV, increased internet media share, digital outdoor media (posters) and other interactive media. Indeed, the future of advertising will increasingly converge with database marketing without losing its focus on attitude creation. Furthermore, these lessons can also be applied to service marketers and their satisfaction studies, giving a further avenue of opportunity for both database and service marketing. Perhaps the most fruitful way of looking at this is to say that the next decade offers great opportunity for the fusion of learning in techniques between the, until now, fragmented disciplines.

At the same time considerably more research is required. For example, while 
CODAR has been proved in more than a dozen brands, there remains considerable opportunity to develop more understanding and expertise in its use as well as more evidence of benefit. No doubt our understanding of consumer minds will be further refined and the techniques for applying it in planning, execution and evaluation enhanced. Taking note of the concern about the responsibility of greater knowledge, as scientists publish more accurate and comprehensive evidence of the working of marketing communication, the scrutiny of citizens and policy makers will increase leading to the need to develop even more robustly ethical practice. In the long run this is likely to increase brand equity. Taken together, this suggests that if we have learned a great deal in the last 20 years, the opportunity exists to learn even more in the next 20 , while gaining significantly more effectiveness right now.

\section{References and Notes}

1 Jenkinson, A. (2006) 'Do organisations now understand the importance of information in providing excellent customer experience?' Journal of Database Marketing \& Customer Strategy Management, Vol. 13, No. 4, pp. 248-260.

2 Jenkinson, A. (1995) 'Valuing your customers, from quality information to quality relationships through database marketing', McGraw Hill, Maidenhead, England.

3 Kuhn, T. S. (1970) 'The structure of scientific revolutions', 3rd Edition, 1996, Chicago University Press, Chicago/London, pp. 10-22.

4 Eisner, E. (1993) 'Objectivity in educational research', in: Hammersley, M. (ed.) 'Educational research: Current issues', Paul Chapman, London, pp. 54-55.

5 Petty, R. E. and Cacioppo, J. T. (1981/96) 'Attitudes and persuasion: Classic and contemporary approaches', West View Press, Boulder, Colorado and Oxford, England, pp. 22-29.

6 Achenbaum, A. (1972) 'Advertising doesn't manipulate consumers', Journal of Advertising Research, April, Vol 12, pp. 3-13.

7 Barnard, N. and Ehrenberg, A. (1997) 'Advertising: Strongly persuasive or nudging?' Journal of Advertising Research, Vol. 37, pp. 21-31.

8 Burkitt, H. (2006) 'Don't shoot the advertising', Market Leader, Autumn, Vol. 34, pp. 19-20.
9 Hall, B. F. (2002) 'A new model for measuring advertising effectiveness', Journal of Advertising Research, Vol. 42, No. 2, pp. 23-32.

10 Allport, G. W. (1935) 'Attitudes', in: Murchison, C. M. (ed.) ' Handbook of social psychology', Clark University Press, Winchester, MA, p. 810.

11 Kotler, P., Armstrong, G., Saunders, J. and Wong, V. (2001) 'Principles of marketing', 3rd European Edition, Financial Times/Prentice Hall, Harlow, Essex, England.

12 Solomon, M., Bamossy, G., Askegaard, S. and Hogg, M. K. (2006) 'Consumer behaviour, a European perspective', Third Edition, Pearson Education, Harlow, Essex.

13 Petty, R. E. and Cacioppo, J. T. (1981/96) op. cit., p. 10.

14 LeDoux, J. (1998) 'The emotional brain', Phoenix, London, p. 27.

15 Hall, A. M. and Maclay, D. (1991) 'How advertisers think advertising works', Davies Riley Smith Maclay, London.

16 Lavidge, R. J. and Steiner, G. A. (1961) 'A model for predictive measurements of advertising effectiveness', Journal of Marketing, Vol. 25, No. 4, pp. 59-62.

17 Hall, B. F. (2002) op. cit.

18 Vakratsas, D and Ambler, T. (1999) 'How advertising works: What do we really know?' Journal of Marketing, Vol. 63, No. 1, pp. 26-43.

19 Hofmeyr, J. and Rice, B. (2000) 'Commitment-led marketing, The key to brand profits is in the customer's mind', John Wiley \& Sons, Chichester, West Sussex, England.

20 Heath, R. G., Brandt, D. and Nairn, A. (2006) 'Brand relationships - Strengthened by emotion, weakened by attention', Journal of Advertising Research, Vol. 46, No. 4, pp. 410-419.

21 Page, G. and Raymond, J. (2006) 'Neuroscience, marketing and research: Separating fact from fiction', ESOMAR Conference CD, Congress 2006-Foresight-The Predictive Power of Research, ESOMAR. ISBN 92-831-0197-9, available on 24/5/2007 at http://www.esomar.org/web/ publication/conference.php?id=102.

22 MacLean, P. D (1990) 'The triune brain in evolution: Role in paleocerebral functions', Plenum Springer, New York, ISBN 0306431688, p. 704.

23 Caine, R. N. and Caine, G. (1990) 'Making connections: Teaching and the human brain', Incentive Publications, Nashville, TN.

24 Damasio, A. (1994) 'Descartes' error: Emotion, reason and the human brain', Grosset/Putnam Book, New York, p. 312.

25 Koenigs, M., Young, L., Adolphs, R., Tranel, D., Cushman, F., Hauser, M. and Damasio, A. (19th April, 2007) 'Damage to the prefrontal cortex increases utilitarian moral judgements', Nature, Vol. 446, pp. 908-911.

26 Goleman, D. (1996) 'Emotional intelligence, why it can matter more than IQ', Bloomsbury Publishing, London, p. 352.

27 Carlgren, F. (1976) 'Education towards freedom: Rudolf Steiner education. A survey of the work of 
Waldorf schools throughout the world', Lanthorn Press, East Grinstead, England.

28 The illustration can be seen as a duck or rabbit.

29 Braun, K. A. (1999) 'Post experience advertising effects on consumer memory', Journal of Consumer Research, Vol. 25, No. 4, pp. 319-332.

30 Heath, R. and Hyder, P. (2005) 'Measuring the hidden power of advertising', International Journal of Market Research, Vol. 47, No. 5, pp. 467-486.

31 Jenkinson, A. (1993) 'From stress to serenity, gaining strength in the trials of life', Sophia Books, Forest Row, UK, pp. 178-194.

32 See for example case studies by Jenkinson, A. and Sain, B. on Centre for Integrated Marketing, www. IntegratedMarketing.org.uk: (2003) Lush, the scent of success; (2003) The Automobile Association: how a big idea put the AA back together; 2003 Specsavers - An Innovative Integrated Marketing Model; (2005) Amazon: bonding customers with integrated service.

33 See for example case studies by Jenkinson, A., and Sain, B. in PMA Educational Foundation (2005, no editor noted) ROI of Integrated Marketing, Sainsbury's, Little Ones; Jenkinson, A., Sain, B. (2005). SEEBOARD Energy, Integrated Marketing transforms the brand fortunes, AOL: redefining marcoms, New York.

34 Jenkinson, A., Sain, B. and Bishop, K. (2005) 'Optimising communication for charity brand management', International Journal of Voluntary Sector and Nonprofit Marketing, Vol. 10, pp. 1-14.

35 Jenkinson, A. (2006) 'Planning and evaluating communications in an integrated organisation', Journal of Targeting, Measurement and Analysis for Marketing, Vol. 15, No. 1, pp. 47-64.

36 Jenkinson, A. and Sain, B. (2004) 'WRC, on track to being a top sports entertainment brand', Centre for Integrated Marketing, www.IntegratedMarketing.org.uk.

37 Razeghi, A. J. and Calder, B. J. (2003) 'Using interaction maps to create brand experiences and relationships', in: Iacobucci, D. and Calder, B. (eds.) 'Kellogg on integrated marketing', John Wiley \& Sons, Hoboken, NJ, pp. 39-53.

38 Fortini, L. (2003) 'Integrated marketing and the consumer experience', in: Iacobucci, D. and Calder, B. (eds.) ' Kellogg on integrated marketing', John Wiley \& Sons, Hoboken, NJ, pp. 54-89.

39 Jenkinson, A. (1995) op. cit., pp 248-258 and 290-291. 